\title{
Mechanical Properties and Biodegradability of the Kenaf/Soy Protein Isolate-PVA Biocomposites
}

\author{
Jong Sung Won, Ji Eun Lee, Da Young Jin, and Seung Goo Lee \\ Department of Advanced Organic Materials \& Textile System Engineering, Chungnam National University, \\ Daejeon 305-764, Republic of Korea \\ Correspondence should be addressed to Seung Goo Lee; 1sgoo@cnu.ac.kr
}

Received 29 January 2015; Revised 29 April 2015; Accepted 30 April 2015

Academic Editor: Mahbub Hasan

Copyright (C) 2015 Jong Sung Won et al. This is an open access article distributed under the Creative Commons Attribution License, which permits unrestricted use, distribution, and reproduction in any medium, provided the original work is properly cited.

\begin{abstract}
The effective utilization of original natural fibers as indispensable components in natural resins for developing novel, low-cost, ecofriendly biocomposites is one of the most rapidly emerging fields of research in fiber-reinforced composite. The objective of this study is to investigate the interfacial adhesion properties, water absorption, biodegradation properties, and mechanical properties of the kenaf/soy protein isolate- (SPI-) PVA composite. Experimental results showed that $20 \mathrm{wt} \%$ poly (vinyl alcohol) (PVA) and $8 \mathrm{wt} \%$ glutaraldehyde (GA) created optimum conditions for the consolidation of the composite. The increase of interfacial shear strength enhanced the composites flexural and tensile strength of the kenaf/SPI-PVA composite. The kenaf/SPI-PVA mechanical properties of the composite also increased with the content of cross-linking agent. Results of the biodegradation test indicated that the degradation time of the composite could be controlled by the cross-linking agent. The degradation rate of the kenaf/SPI-PVA composite with the cross-linking agent was lower than that of the composite without the cross-linking agent.
\end{abstract}

\section{Introduction}

Biodegradable polymers that are derived from natural resources are potential substitutes for existing petroleumbased synthetic polymers, owing to their low cost, easy availability, and complete biodegradability [1]. Among various cellulose, starch, and protein materials, soy protein isolate (SPI) is used to form packaging and edible film because of its excellent film forming abilities, good biodegradable performance, and high barrier against oxygen and oil in low humidity conditions $[2,3]$. However, the low mechanical properties and high moisture sensitivity of soy protein-based plastics have limited their usage [4]. These characteristics are attributed to the inherent hydrophilicity of natural proteins and the amount of hydrophilic plasticizer incorporated into them. Moreover, literature [5] has confirmed that SPI films that lack secondary components do not show good mechanical and barrier properties.

Soy protein is commercially available as SPI, soy protein concentrate (SPC), and soy flour (SF). Chemically, SPI contains $90 \%$ protein, while SPC contains $70 \%$ and $18 \%$ carbohydrates and $6 \%$ ash, with fiber and moisture making up the remaining components. SF contains up to $55 \%$ protein and $32 \%$ carbohydrates. Soybean protein contains several amino acids, such as glutamic acid, arginine, lysine, cysteine, and aspartic acids, which have polar groups. These groups can act as useful cross-linking and/or hydrogen bonding sites to improve the mechanical properties of soy protein polymers. In the present research, SPI was modified with GA to increase its mechanical and physical properties and to improve thermal stability and processability as a matrix for composite fabrication. Several researchers have studied the cross-linking of GA with proteins and confirmed the reaction mechanisms [6]. Biswas et al. [7] and Gellerstedt and Gatenholm [8] have proposed that the GA reacts with the amino groups in protein to form cross-links. Zini et al. [9] used maleinized tung oil to cross-link the SPI and improve its tensile properties. A typical cross-linked structure of soy protein with the GA is shown in Figure 1 [6]. It was, however, difficult to assess the average degree of cross-linking because of the complexity of the chemistry. The cross-linking was judged based on the improved tensile strength and interfacial adhesion properties and decreased fracture strain and moisture absorption after the GA modification as well as 


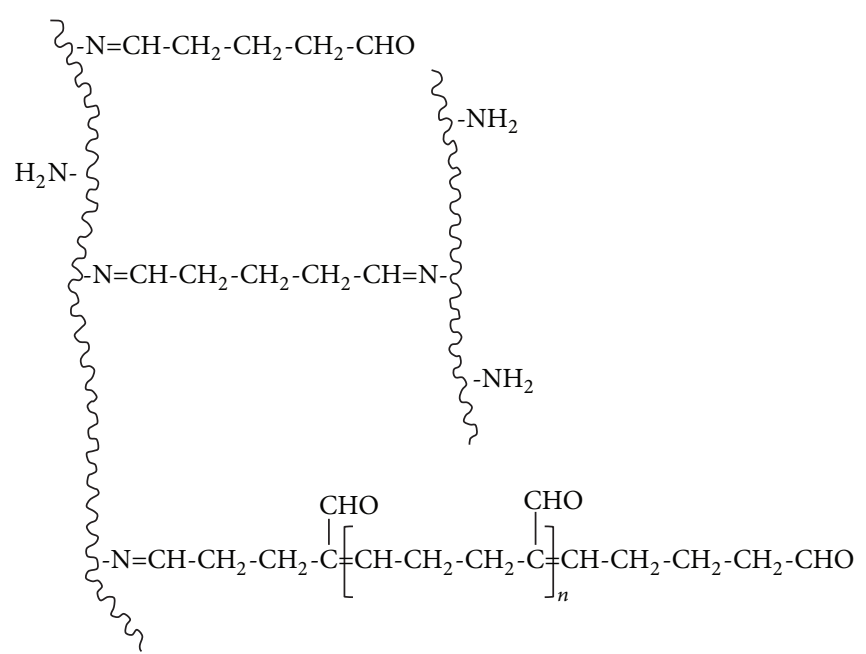

FIGURE 1: Schematic structure of the glutaraldehyde (GA) cross-linked soy flour.

the significant increase in the viscosity immediately following the addition of GA to the SPC solution [10].

Another approach to modify the moisture sensitivity of SPI films is to blend other natural or synthetic polymers with SPI materials [11]. Normally, biodegradable polymers such as gelatin, starch, cellulose, and protein are used as blend components to ensure that the final films can still be considered "green." However, because natural polymers are inherently hydrophilic, these blends cannot solve the moisture sensitivity problem of SPI films. In addition to natural materials, PVA, the world's most produced synthetic, watersoluble polymer, can be blended with natural polymers to form biodegradable composites. These PVA/natural polymer blends have promising industrial applications in many fields because of their biodegradability, biocompatibility, chemical resistance, and excellent physical properties [11].

Biocomposites composed of natural fibers and synthetic or natural polymer matrices have gained recent attention due to their cost effectiveness, low density, biodegradability, ready availability, energy recovery, and $\mathrm{CO}_{2}$ sequestration [12]. The natural fibers commonly used to reinforce biocomposites are jute, flax, hemp, ramie, sisal, bamboo, and kenaf fiber [13]. The renewable and biodegradable characteristics of these natural fibers enable disposal processes, which are not possible with most industrial fibers.

Among others, kenaf offers the particular advantages of a fiber crop, including rapid growth in various climatic conditions and, subsequently, the prompt accumulation of carbon dioxide [14]. Kenaf fiber, obtained by processing the bark of the kenaf plant, exhibits low density and nonabrasiveness during processing, highly specific mechanical properties, and biodegradability. Due to their similarities, kenaf can be used either as an alternative to or in admixture with jute. In 1995, kenaf was priced at $\$ 400$ per tonne and from $\$ 278$ to $\$ 302$ per tonne in 2000 [15]. It takes $54 \mathrm{MJ}$ to produce $1 \mathrm{~kg}$ of glass fiber, but only $15 \mathrm{MJ}$ of energy to produce $1 \mathrm{~kg}$ of kenaf. Kenaf has been largely used to reinforce thermoplastic polymers $[16,17]$ and, recently, thermoset polymers [18]. Kenaf fibers have also been used as nonwoven mats in the automotive, textile, fiberboard, civil, and electronic industries [19-21].

Until recently, studies on SPI/PVA blends reported the use of plasticizers and cross-linking agents to increase mechanical and physical properties, improve thermal stability, reduce moisture absorption, and improve processability as a resin for composite fabrication. Biocomposites reinforced with kenaf fiber that use a SPI/PVA blend have not been reported, despite their many advantages of biodegradability, biocompatibility, chemical resistance, and excellent physical properties. In this study kenaf nonwovens were used to fabricate environment friendly biocomposites using modified SPIbased resins. SPI was modified using PVA in order to improve the interfacial bonding of kenaf nonwoven/SPI and then cross-linked with GA to improve its mechanical properties and water resistance. The biodegradation of the biocomposites was analyzed to determine the effect of PVA and the crosslinking agent on the composting of the kenaf composites.

\section{Experimentals}

2.1. Materials. SPI with an approximate protein content of 90\% was supplied by Solea Company, USA. GA (grade II, $25 \%$ solution), glycerol, and PVA ( $98 \%$ hydrolyzed, average molecular weight (Mw) of 89,000-98,000) were obtained from Sigma-Aldrich Chemical Company. Kenaf nonwovens with an areal density of $400 \mathrm{~g} / \mathrm{m}^{2}$ were obtained from KumHa Co. Ltd. (Korea).

\subsection{Preparation of the SPI/PVA Film and Kenaf/SPI-PVA} Composite. The SPI/PVA films were prepared using a casting method. First, the SPI (10 wt\%) and PVA (5 wt\% 20 wt\%) were dissolved in water $(\mathrm{pH} 8)$ and cured at $70^{\circ} \mathrm{C}$ for 25 minutes. Second, $20 \mathrm{wt} \%$ glycerol was added according to the optimum condition [22]. Prepared solution was casted on a glass plate and dried at $40^{\circ} \mathrm{C}$ for 24 hours. Finally, the SPI/PVA film was cured at $140^{\circ} \mathrm{C}$ via hot pressing for 10 minutes, under a pressure of $7 \mathrm{MPa}$. 


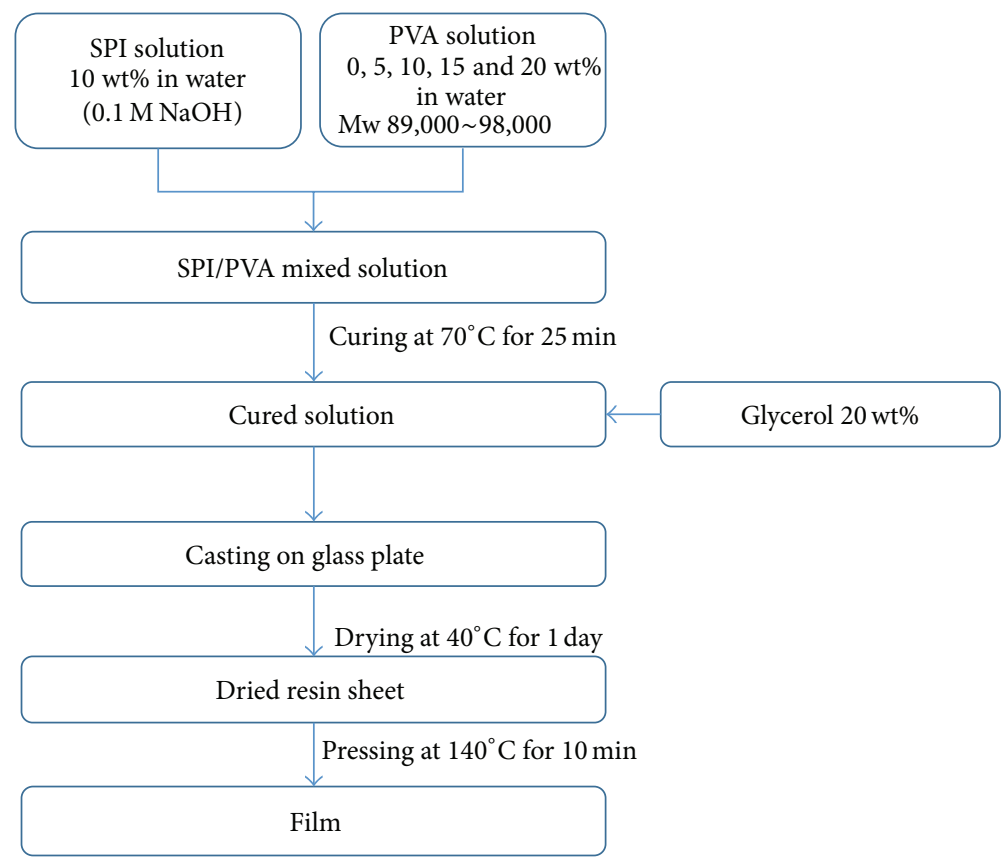

FIGURE 2: Manufacturing process of the SPI/PVA film.

Kenaf nonwovens were dewaxed by soaking them in a mixture of ethanol and benzene $(1: 2)$ at $50^{\circ} \mathrm{C}$ for 5 hours and then washed with distilled water and air dried. The dewaxed nonwovens were immersed in a $10 \mathrm{wt} \%$ aqueous sodium hydroxide solution at $30^{\circ} \mathrm{C}$ for 1 hour and then washed with distilled water and dried. To remove any remaining moisture, the pretreated kenaf nonwoven was cut into $20 \mathrm{~cm}$ by $20 \mathrm{~cm}$ pieces and dried at $100^{\circ} \mathrm{C}$ for 2 hours in a dryer and at $80^{\circ} \mathrm{C}$ for 3 hours in a vacuum oven. Kenaf nonwoven reinforced composites were fabricated using SPI (10 wt $\%) /$ PVA (15 wt $\%)$ resins added glycerol (20 wt\%)/GA (0 wt $\%$ 25 wt $\%)$. The manufacturing process of the SPI/PVA film and kenaf/SPIPVA composite are shown in Figures 2 and 3, respectively. The purposes of adding glycerol in kenaf/SPI-PVA composite were to improve the toughness and to make the kenaf/SPIPVA composite more flexible.

\subsection{Measurements}

2.3.1. Water Absorption. The initial weight of the kenaf/SPIPVA composite with the cross-linking agent was measured and the specimen submerged in distilled water at $25^{\circ} \mathrm{C}$ for 12 hours. Water absorption was calculated using (1), in which $W_{\text {wet }}$ and $W_{\text {dry }}$ represent weight of the sample after immersed in water and initial weight of the sample, respectively:

$$
\text { Water absorption }(\%)=\frac{W_{\text {wet }}-W_{\text {dry }}}{W_{\text {dry }}} \times 100 \text {. }
$$

2.3.2. Mechanical Properties. To investigate the effects of PVA and the cross-linking agent on the mechanical properties of SPI, tensile and flexural (three-point bending) tests were performed at a cross-head speed of $5 \mathrm{~mm} / \mathrm{min}$ using an Instron (model 4467), according to ASTM D638 and ASTM D790, respectively. The value of each mechanical property was determined by an average of ten specimens.

2.3.3. Interfacial Adhesion Test. The interfacial shear strength (IFSS) between the kenaf fiber and SPI was measured by a microdroplet debonding test using an Instron test system (model 4467) equipped with a $500 \mathrm{~N}$ load cell. The microdroplet test specimen of kenaf fiber with SPI was made to composite at $80^{\circ} \mathrm{C}$ for 24 hours. Figure 4 shows the test grip and microvise for the microdroplet debonding test. Tests were performed at a cross-head speed of $1 \mathrm{~mm} / \mathrm{min}$ at room temperature. The maximum force $\left(F_{\max }\right)$ was recorded to calculate the interfacial shear strength $\left(\tau_{\max }\right)$ using $(2)$, in which $D$ and $L$ represent fiber diameter and fiber embedded length, respectively:

$$
\tau_{\max }=\frac{F_{\max }}{\pi D L} .
$$

2.3.4. Morphology. The surface and fracture morphologies of the kenaf/SPI-PVA composite were observed with a scanning electron microscope (SEM, S4700, HITACHI).

2.3.5. FTIR Analysis. A Fourier transform infrared spectrophotometer (FT-IR, Bruker Optic GmbH, ALPHA-P) equipped with an attenuated total reflectance (ATR) accessory was used to examine the surface composition of the uncross-linked and cross-linked kenaf/SPI-PVA composite. The spectra were recorded in the transmission mode in the range of $4000-500 \mathrm{~cm}^{-1}$. FT-IR spectra were measured at a spectral resolution of $4 \mathrm{~cm}^{-1}$, and the spectra were obtained with an accumulation of 128 scans for a high signal-to-noise ratio. 


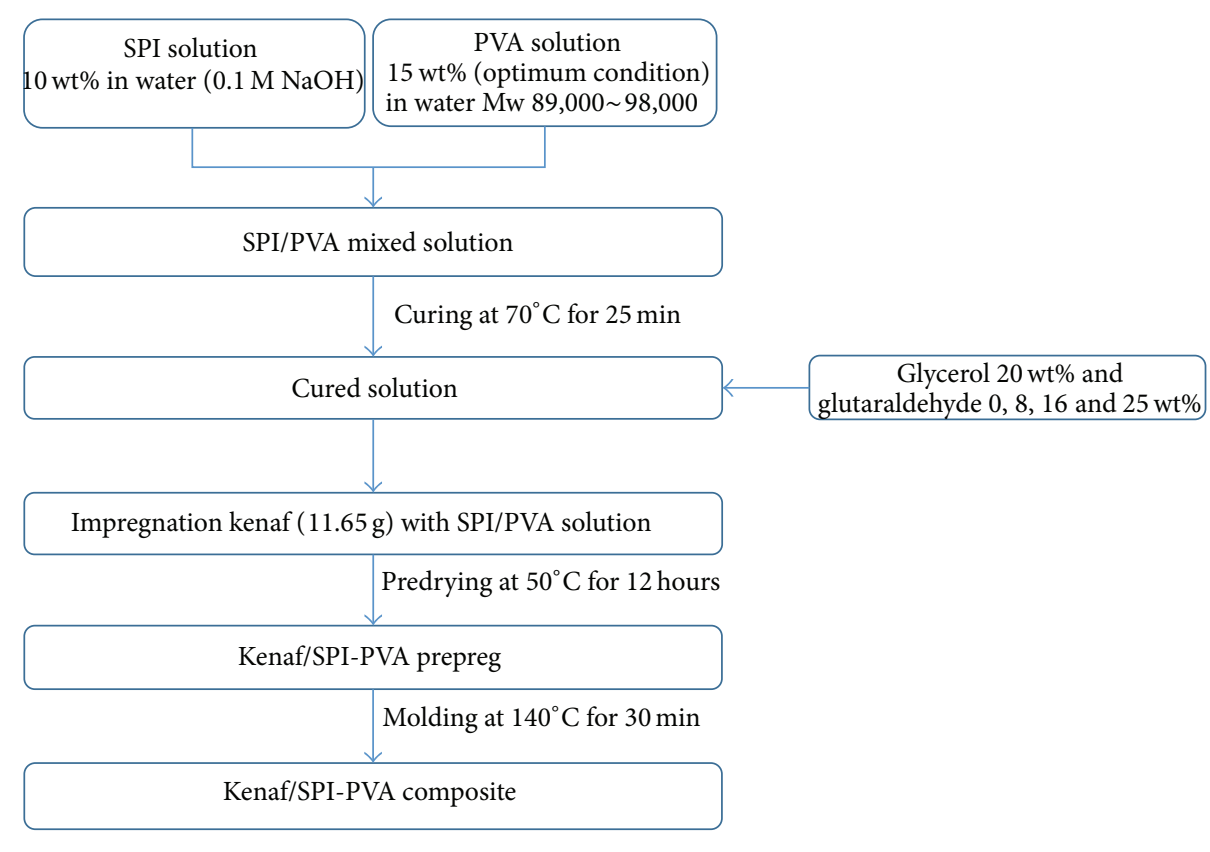

FIGURE 3: Manufacturing process of the kenaf/SPI-PVA composite.

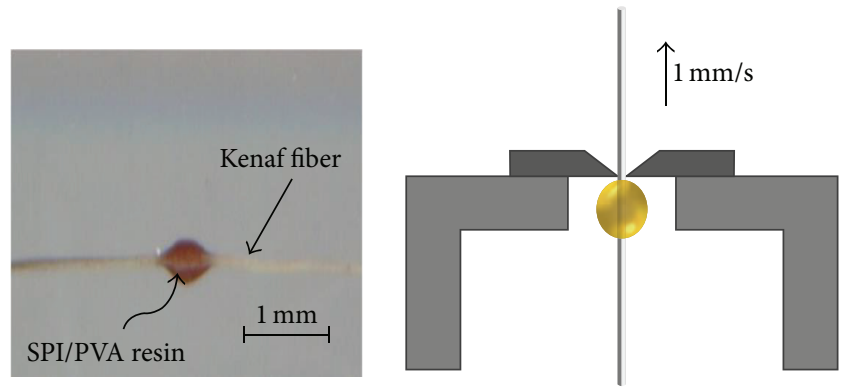

FIGURE 4: Photograph and schematic diagram of the microdroplet debonding test sample and test setup.

2.3.6. Biodegradation. Test specimen of the kenaf/SPI-PVA composites containing the cross-linking agent was prepared in equal amounts of the size of $20 \mathrm{~mm} \times 20 \mathrm{~mm}$. They were dried in a vacuum oven for 2 hours. Specimens were mixed with the compost in a test bath (as shown in Figure 5) at $58 \pm$ $2^{\circ} \mathrm{C}$, using a constant temperature bath. To maintain aerobic environment, air was injected continuously at $200 \mathrm{cc}$ per minute during the test. Weight changes were measured after the specimen was dried in a vacuum oven for 12 hours at $50^{\circ} \mathrm{C}$.

\section{Results and Discussion}

\subsection{Effect of PVA Content on SPI/Glycerol Film}

3.1.1. Tensile Properties. Figures 6 and 7 show the effect of PVA content on the tensile properties of SPI film without and with glycerol. The following results can be concluded from the data: (Figure 6) For the SPI/PVA films without glycerol, tensile strength decreased with the increase of PVA

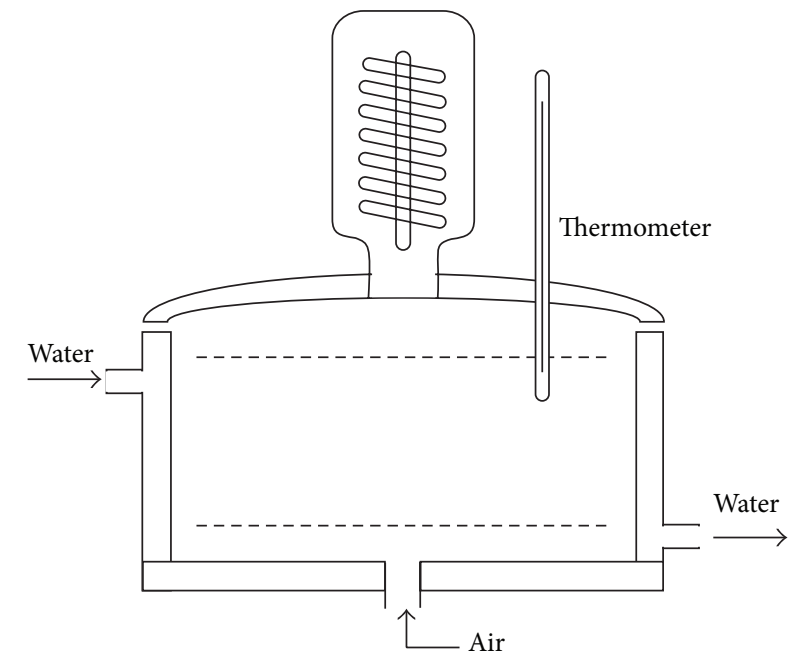

FiguRE 5: Schematic diagram of biodegradation test chamber.

content. (Figure 7) Comparing to the SPI/PVA films without glycerol, after adding glycerol (20 wt\%), tensile strength of each SPI/PVA film increased and tensile modulus of it decreased with the content of glycerol. These behaviors are due to the plasticization effect of glycerol. Consequently, $15 \mathrm{wt} \%$ of PVA was chosen as an optimum condition. Enhancement of mechanical properties is attributed to the long-chain PVA molecules which contain many negative $\mathrm{OH}$ groups, forming strong intra- and intermolecule interactions with the protein molecules. These interactions may include hydrogen-bonding, dipole, and charge effects. In addition, blending long molecules in SPI could bring about molecular entanglements, which in turn will improve the mechanical properties of SPI [23]. 


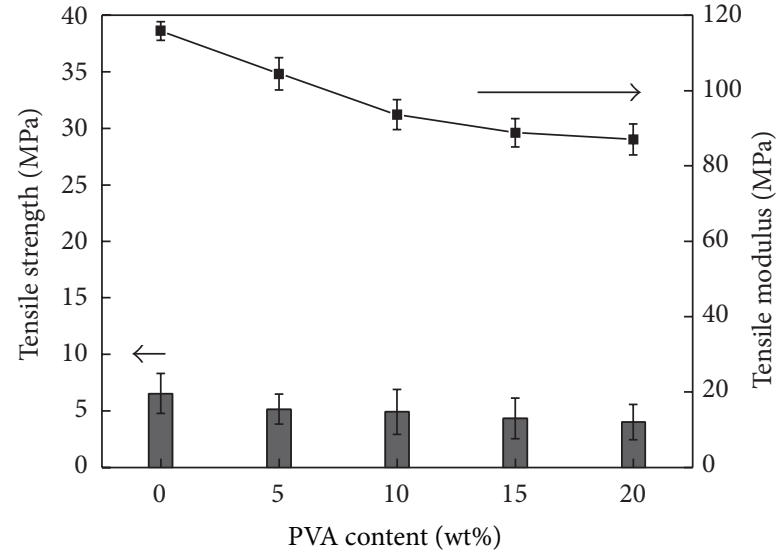

FIgURE 6: Tensile properties of the SPI film without PVA content.

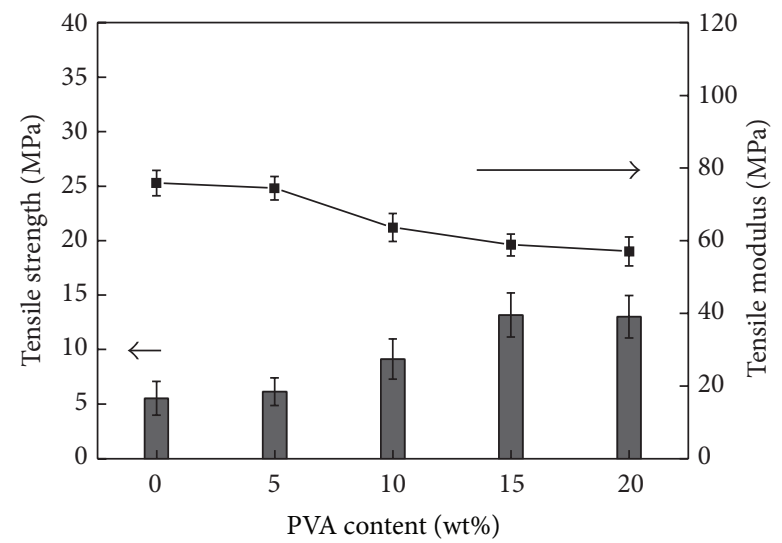

Figure 7: Tensile properties of the SPI/glycerol film with PVA content.

3.1.2. FTIR Analysis. The FTIR spectra of the SPI/glycerol film with and without PVA are shown in Figure 8(a). Pure glycerol is known to show absorption peaks corresponding to C-C and C-O groups in the fingerprint region from $800 \mathrm{~cm}^{-1}$, $1150 \mathrm{~cm}^{-1}$ wavenumbers as reported by Lodha and Netravali [24]. The FTIR spectra of the SPI/glycerol without PVA show five peaks at $850 \mathrm{~cm}^{-1}, 900 \mathrm{~cm}^{-1}, 925 \mathrm{~cm}^{-1}$ (C-C skeletal vibrations), $1045 \mathrm{~cm}^{-1}$ (C-O stretch at $\mathrm{C}^{1}$ and $\mathrm{C}^{3}$ ), and $1117 \mathrm{~cm}^{-1}$ (C-O stretch at $\mathrm{C}^{2}$ ) wavenumbers indicating the presence of glycerol on the specimen surface. Similar results for SPI/glycerol film have also been previously reported [24, 25]. Also, the absorption peak of $1480 \mathrm{~cm}^{-1}$ to $1570 \mathrm{~cm}^{-1}$, $1600 \mathrm{~cm}^{-1}$ to $1700 \mathrm{~cm}^{-1}$, and $3294 \mathrm{~cm}^{-1}$ in SPI refers to the hydrogen bond between protein chains and moisture in protein and carbonyl groups [23].

Figure 8(b) shows the FTIR spectra of SPI/glycerol film with PVA. The basic structure of the PVA molecule is - OH groups on carbon chains. The broad - $\mathrm{OH}$ absorption band was observed in the wavenumber range of $2918 \mathrm{~cm}^{-1}$ to $3565 \mathrm{~cm}^{-1}$. As can be seen in spectra of the SPI/glycerol film with PVA, new absorption bands appeared in comparison

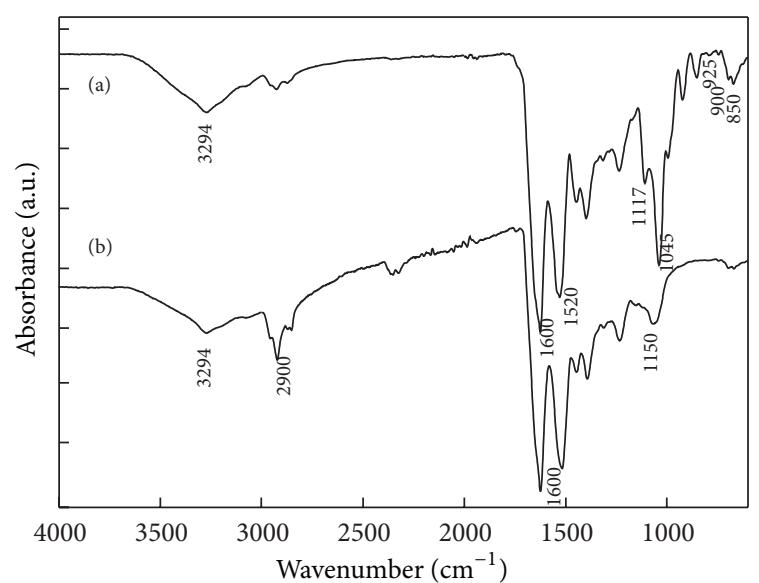

(a) SPI/glycerol without PVA

(b) SPI/glycerol with PVA

FIGURE 8: FTIR spectra of SPI/glycerol without and with PVA.

to the SPI/glycerol film without PVA. The absorption bands at 1600 to $1400 \mathrm{~cm}^{-1}$ and 1150 to $1250 \mathrm{~cm}^{-1}$ are attributable to $-\mathrm{NH}-, \mathrm{C}-\mathrm{N}$ stretching, and $\mathrm{N}-\mathrm{H}$ bending (amide III) vibrations, respectively. A typical characterization of these spectra is the disappearance of the strong hydrogen bond appearing both in SPI and PVA spectra, whereas a new absorption band at 2900 to $3100 \mathrm{~cm}^{-1}$ appears. Normally, the absorption band of 2918 to $3565 \mathrm{~cm}^{-1}$ accords with the lapped characteristic band of -OH for moisture in SPI and PVA as mentioned earlier [23].

3.1.3. Morphology Observation. Figures 9(a) and 9(b) typically show the SEM photographs of SPI/glycerol film without and with PVA. Obviously, SPI/glycerol films can be fabricated smoothly without cracks and microholes. With the addition of PVA in SPI/glycerol, the surfaces have some rimples, which might owe to the toughening effect of little molecules.

SEM photographs of the fractured surface of the SPI/PVA film after the tensile test are shown in Figure 10(a). The SPI film without PVA showed a brittle fracture behavior and a shear fractured cross section due to fast crack propagation. With the increase of PVA content in the SPI, the blend materials become less brittle, as shown in Figures 10(b), 10(c), and $10(d)$.

\subsection{Effect of GA Content on Kenaf/SPI-PVA Composites}

3.2.1. FTIR Analysis. The FTIR spectra of the uncross-linked and cross-linked kenaf/SPI-PVA composite are shown in Figure 11. As can be seen in spectra of the cross-linked kenaf/SPI-PVA composite, most characteristic absorption bands appear with addition of SPI, PVA, and GA. As mentioned earlier in Section 3.1.2, the cross-linking of the kenaf/SPI-PVA composite was confirmed by strong hydrogen bond, -NH-, C-N stretching, and $\mathrm{N}-\mathrm{H}$ bending vibrations after curing treatment, as compared to uncured kenaf/SPIPVA composite. 


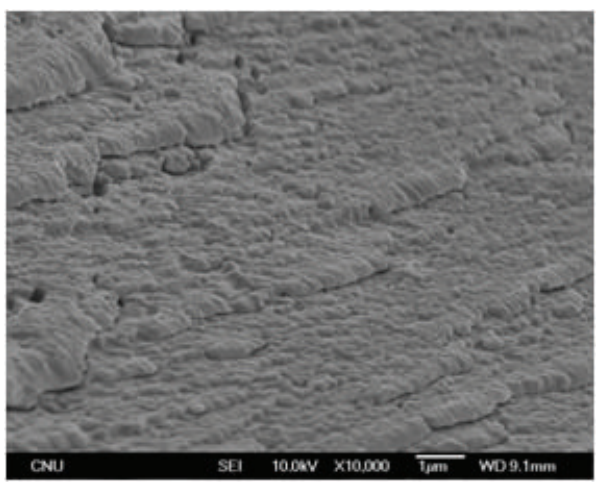

(a)

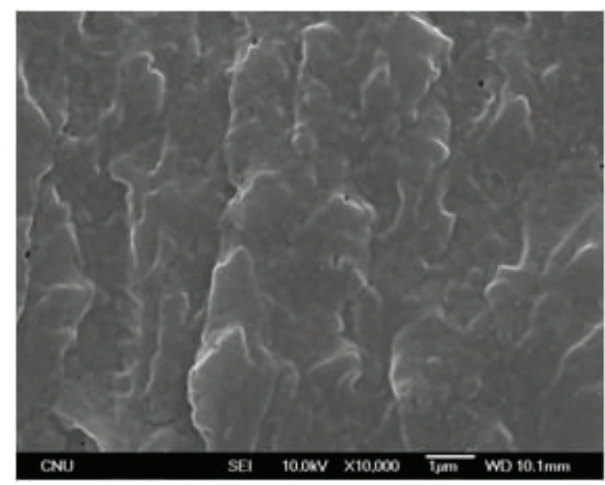

(b)

FIGURE 9: SEM photographs of surface of (a) SPI/glycerol without PVA, (b) SPI/glycerol film with PVA.

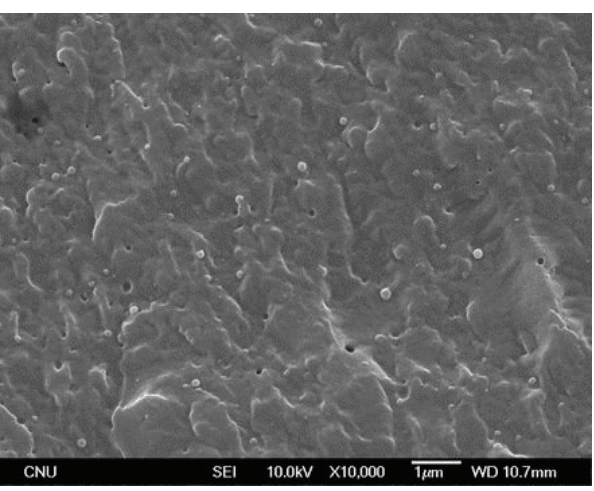

(a)

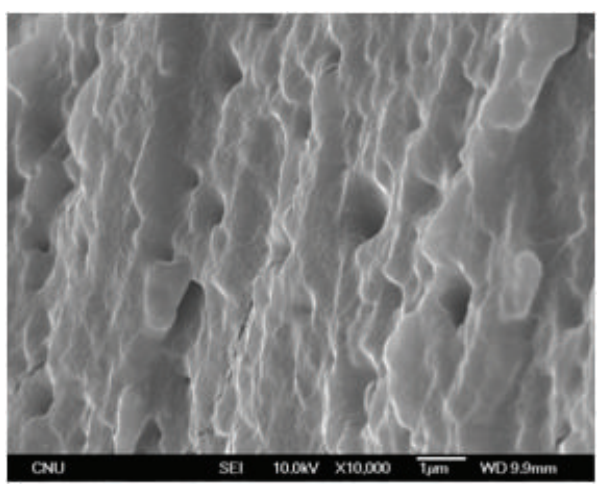

(c)

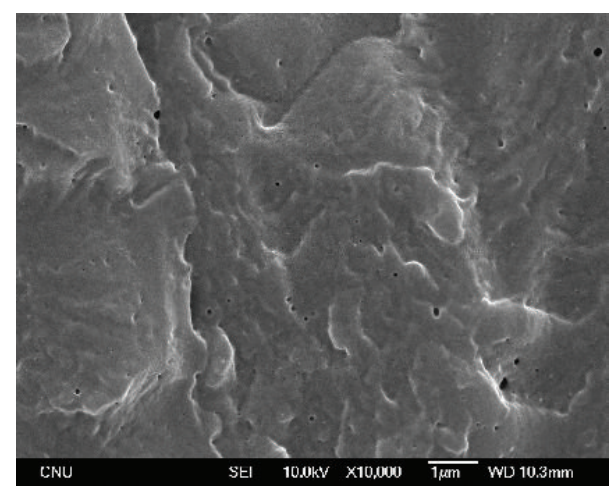

(b)

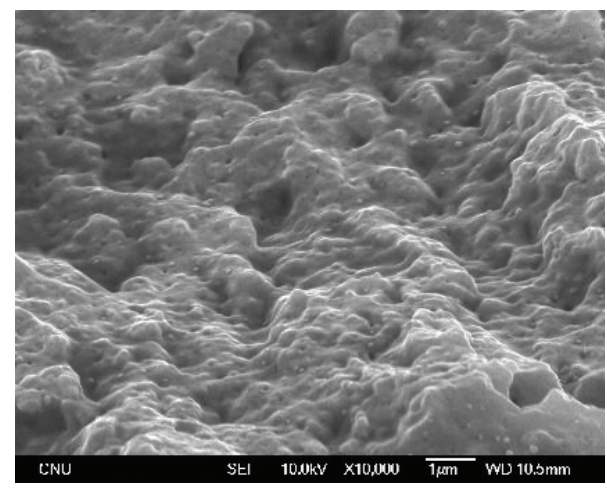

(d)

FIGURE 10: SEM photographs of tensile fracture surface of (a) neat SPI/glycerol film, (b) SPI/glycerol film with PVA (5 wt\%), (c) SPI/glycerol film with PVA (15 wt\%), and (d) SPI/glycerol film with PVA (20 wt \%).

3.2.2. Interfacial Adhesion Properties. The interfacial adhesion strength was examined whether the addition of GA could improve adhesion between the kenaf fiber and the SPI. The average of thirty specimens was used to evaluate the IFSS as a manifestation of adhesion strength. The IFSS of the kenaf/SPI-PVA composite according to the added amount of GA is shown in Figure 12. The IFSS showed a maximum value of $15.03 \mathrm{MPa}$ with the addition of $8 \mathrm{wt} \% \mathrm{GA}$. However, the IFSS of the kenaf/SPI-PVA composite with an added GA of $16 \mathrm{wt} \%$ and $25 \mathrm{wt} \%$ decreased, indicating that the blend becomes brittle when highly cross-linked with GA.

The effect of the IFSS on tensile properties of the kenaf/SPI-PVA composites is shown in Figure 13. There is a proportional relationship between tensile strength and IFSS. Tensile strength of the kenaf/SPI-PVA composites increased from $17 \mathrm{MPa}$ to $23 \mathrm{MPa}$ when the IFSS was raised from 10.14 $\mathrm{MPa}$ to $15.03 \mathrm{MPa}$, as compared to $10.14 \mathrm{MPa}$ IFSS. The increased tensile strength of the kenaf/SPI-PVA composites 


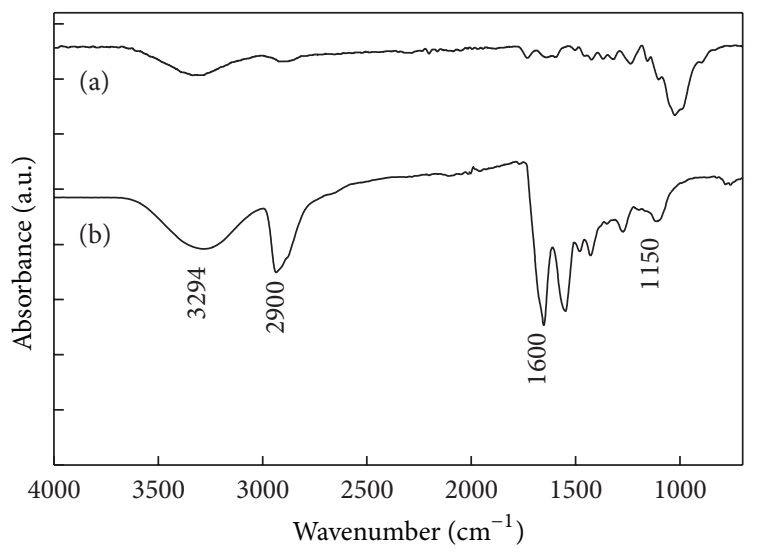

(a) Uncrosslinked kenaf/SPI-PVA composite

(b) Cross-linked kenaf/SPI-PVA composite

FIGURE 11: FTIR spectra of the uncross-linked and cross-linked kenaf/SPI-PVA composite.

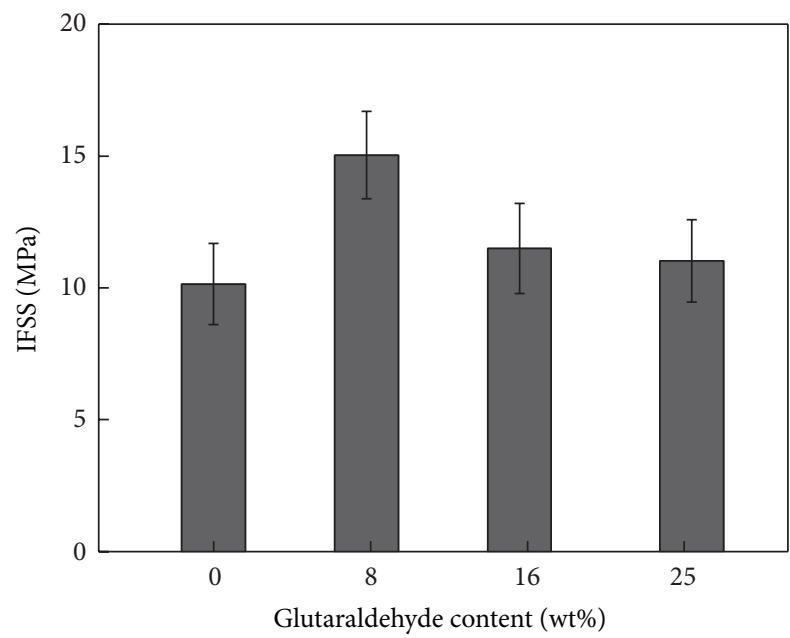

FIGURE 12: Interfacial adhesion properties of the kenaf/SPI-PVA composites with GA content.

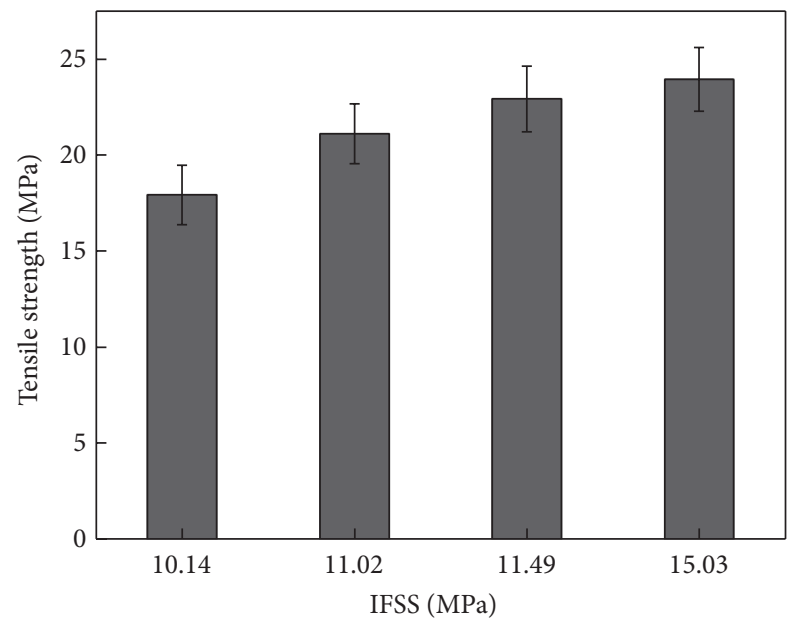

FIGURE 13: Relationship between tensile strength and IFSS of the kenaf/SPI-PVA composites. indicates a good adhesion between kenaf fiber and SPI/PVA matrix when $8 \mathrm{wt} \% \mathrm{GA}$ is added.

3.2.3. Mechanical Properties. Flexural and tensile properties of the kenaf/SPI-PVA composite with GA are shown in Figures 14 and 15. In cases of $16 \mathrm{wt} \%$ GA content, the flexural strength and modulus of the kenaf/SPI-PVA composite increased to $39 \mathrm{MPa}$ and $2662 \mathrm{MPa}$, respectively. However, the flexural strength and modulus slightly decreased at the higher GA content, as shown in Figure 14. The slight decrease of flexural properties is well known such that internal stresses occur during the excessive cross-linking of thermosets and these residual stresses play an important role in flexural fracture. Residual stress build-up has been extensively studied in epoxy polymers and acrylate networks, and so forth [26]. It has to be noticed that excessive residual stresses in matrix and interface have been a reason of low compressive or flexural stress.

In Figure 15, while there appears to be little difference in tensile strengths of the kenaf/SPI-PVA composites with GA content, most of tensile strength is higher than those of the uncross-linked composite. Tensile modulus of the kenaf/SPI-PVA composite showed an increasing tendency with GA, while tensile strength did not show it. The increase in tensile modulus with GA addition can be attributed to the cross-links formed by GA with kenaf/SPI-PVA. Park et al. [27] showed that cross-linking SPI with GA increased the tensile properties from 8.3 to $14.9 \mathrm{MPa}$. They suggested that the covalent intermolecular and intramolecular cross-linking between soy protein and GA increased the mechanical properties of SPI/GA films.

3.2.4. Water Absorption. Water absorption properties of the cross-linked kenaf/SPI-PVA composite with the crosslinking agent after immersion in a water tank at $25^{\circ} \mathrm{C}$ for 12 hours are shown in Figure 16. Most of the water absorption of kenaf/SPI-PVA composite decreased with the cross-linking agents. As the GA content increased, water absorption decreased from $40.5 \%$ to $22.2 \%$. Due to the crosslinking effect of GA, compact structure of the composite less absorbs the external moisture.

3.2.5. Fracture Surface. SEM photographs of the surface and fracture surface of the kenaf/SPI-PVA composites are shown in Figure 17. The surface and fracture surface of the composite without a cross-linking agent are shown in Figure 17(a), in which the kenaf fiber does not fully adhere to the SPI/PVA resin. The kenaf/SPI-PVA composites with a cross-linking agent were observed smooth interfacial bond between kenaf and SPI-PVA. As the interfacial bond mainly depended on the number of entangled chains forming connections across the interface, the strong bond indicated that the molecules of kenaf/SPI-PVA composites could yield more entanglement at $8 \mathrm{wt} \% \mathrm{GA}$. Obviously, many of cracks were observed in Figure 17(d) of the composite having $25 \mathrm{wt} \%$ of glutaraldehyde. These cracks might affect mechanical properties and fracture of the composite. Also, internal stresses in composites might occur during the excessive cross-linking as mentioned earlier. 


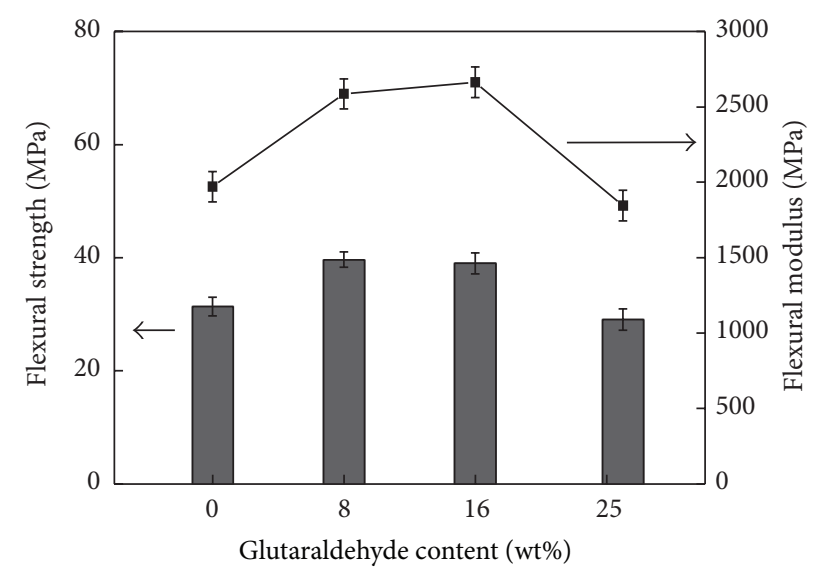

FIGURE 14: Flexural properties of the kenaf/SPI-PVA composites with GA content.

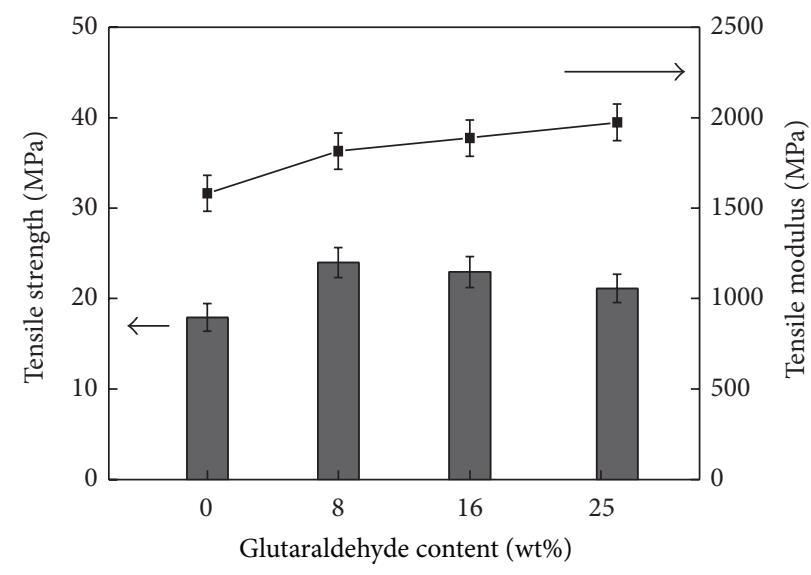

FIGURE 15: Tensile properties of the kenaf/SPI-PVA composites with GA content.

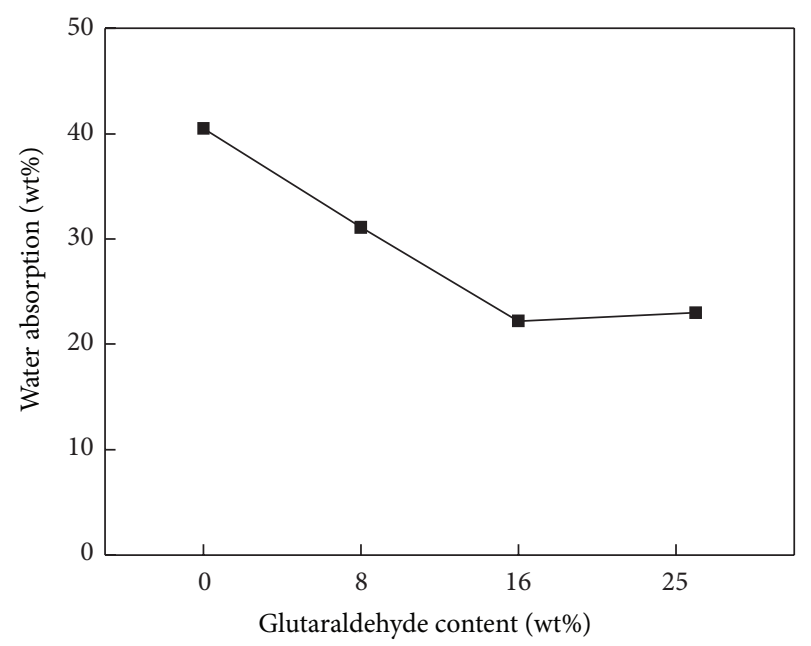

FIGURE 16: Water absorption of cross-linked kenaf/SPI-PVA composites with GA content.
3.2.6. Biodegradation Properties. The weight changes of the kenaf/SPI-PVA composite specimen, according to biodegradability, are shown in Figure 18. The weight of the kenaf/SPI-PVA composite without GA (a) decreased by approximately $22 \%$ after 5 days and approximately $43 \%$ after 20 days in a compost condition. The kenaf/SPI-PVA composite film with $8 \mathrm{wt} \%$ GA (b) showed a lower value of weight loss than the uncross-linked composite. Weight of the cross-linked kenaf/SPI-PVA composite decreased by approximately $12 \%$ after 5 days in a compost condition and $16 \%$ after 20 days. This indicated that the durability of the kenaf/SPI-PVA composite in a compost condition was enhanced by cross-linking with GA.

Photographs of the specimen under biodegradation conditions are shown in Figure 19. In the biodegradation test, moisture and temperature affected the biodegradation of the specimen. The kenaf/SPI-PVA composite without a crosslinking agent (a) was decomposed more in the compost than the cross-linked composite. In the kenaf/SPI-PVA composite with a cross-linking agent (b), however, biodegradability depended on the addition of GA rather than PVA $[6,20]$. Considering biodegradation behavior, it can be concluded that the cross-linking of the kenaf/SPI-PVA composite with GA might govern the biodegradability. According to the biodegradation, by-products of microorganism appeared on the specimen's surface.

\section{Conclusions}

In this study, the kenaf/SPI-PVA compositeswere prepared with plasticizers and a cross-linking agent. Their interfacial adhesion properties, water absorption, biodegradation, and mechanical properties were analyzed. Results were as follows:

(i) Increase of tensile strength in the kenaf/SPI-PVA composites indicated a good adhesion between kenaf fiber and SPI/PVA when GA of $8 \mathrm{wt} \%$ was added to the kenaf/SPI-PVA composites.

(ii) Through the use of the cross-linking agent, the water absorption of the kenaf/SPI-PVA composite decreased. When GA $16 \mathrm{wt} \%$ was added, water absorption of the kenaf/SPI-PVA composite decreased significantly.

(iii) The optimum preparation condition for the kenaf/ SPI-PVA composite was established at PVA $15 \mathrm{wt} \%$ as a plasticizer and GA $8 \mathrm{wt} \%$ as a cross-linking agent.

(iv) In the biodegradation test, degradation was controlled by the cross-linking agent GA. The degradation rate of the kenaf/SPI-PVA composite with GA was lower than the composite without GA, because the cross-linking between the kenaf fiber and SPI/PVA in the composite restricted its biodegradation.

\section{Conflict of Interests}

The authors declare that there is no conflict of interests regarding the publication of this paper. 

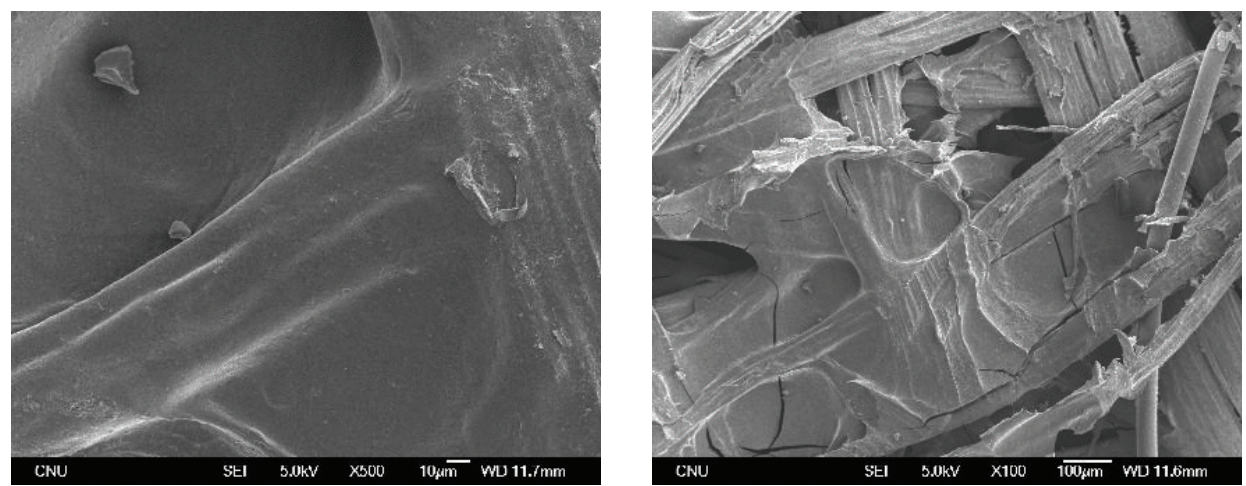

(a)
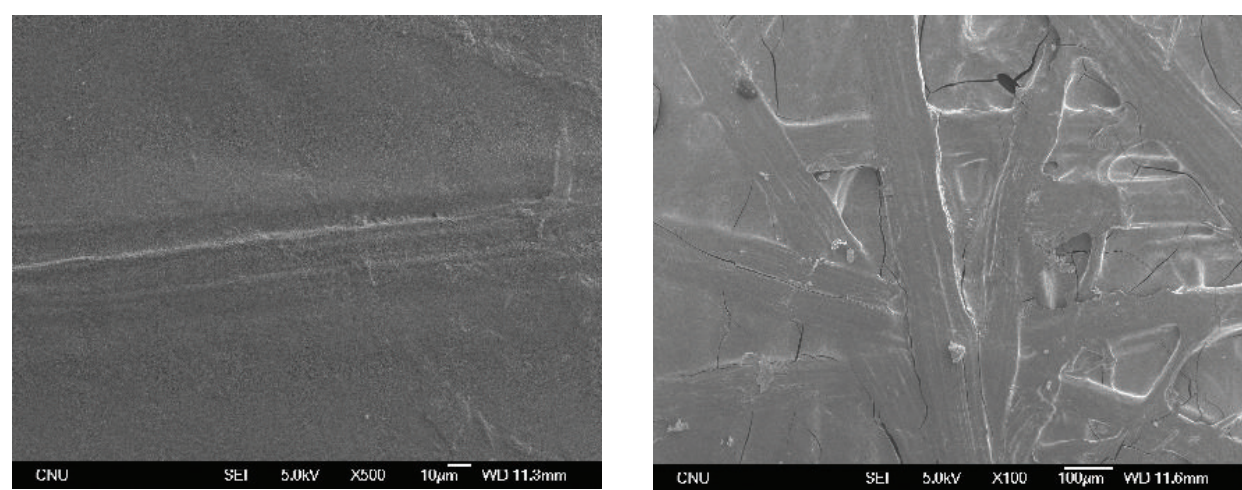

(b)
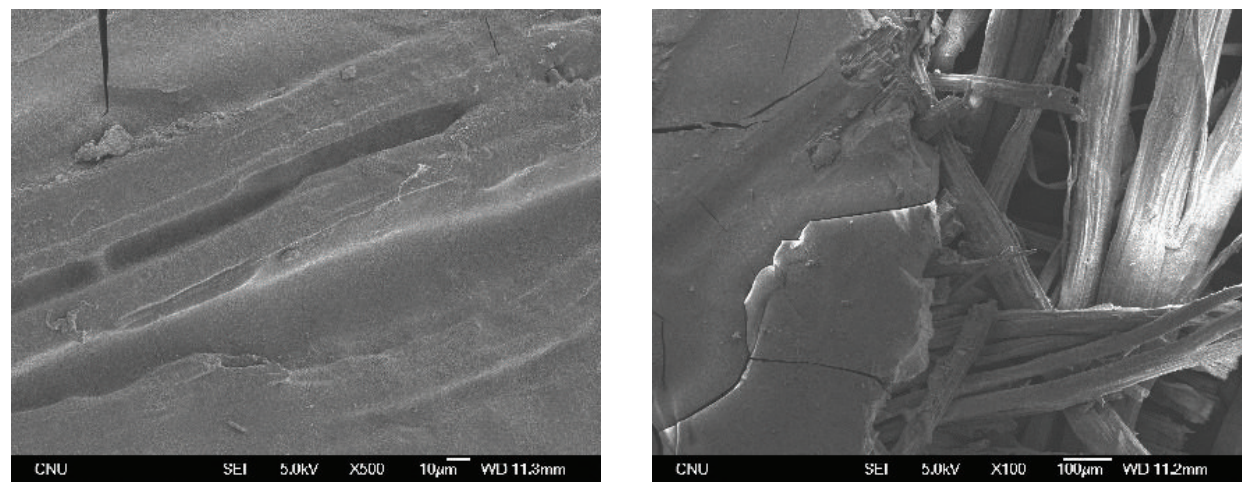

(c)
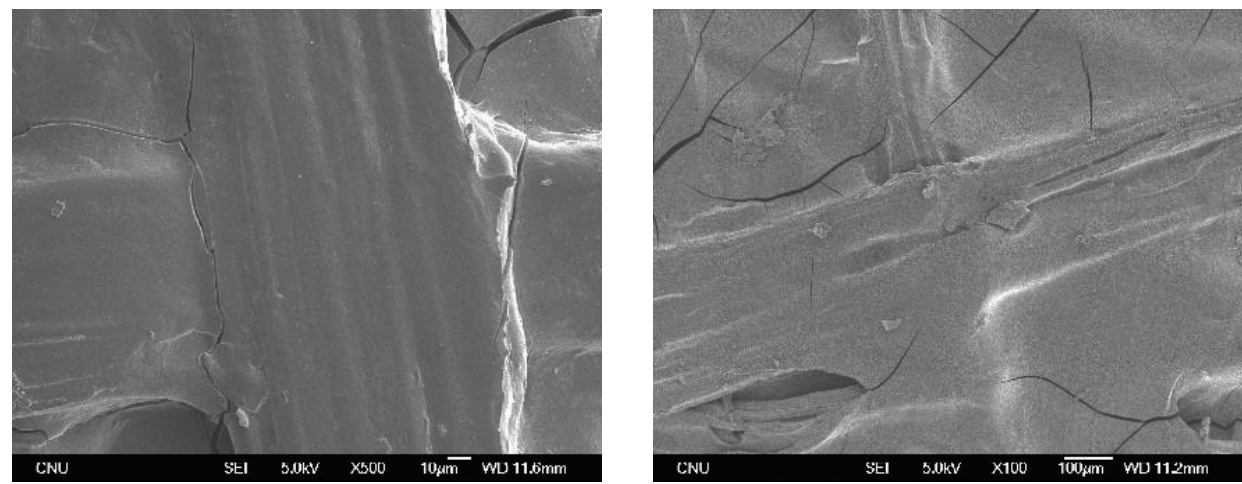

(d)

Figure 17: Surfaces (left, $\times 500$ ) and fracture surfaces (right, $\times 100$ ) of the kenaf/SPI-PVA composites with GA content: (a) 0 wt $\%$, (b) 8 wt $\%$, (c) $16 \mathrm{wt} \%$, and (d) $25 \mathrm{wt} \%$. 


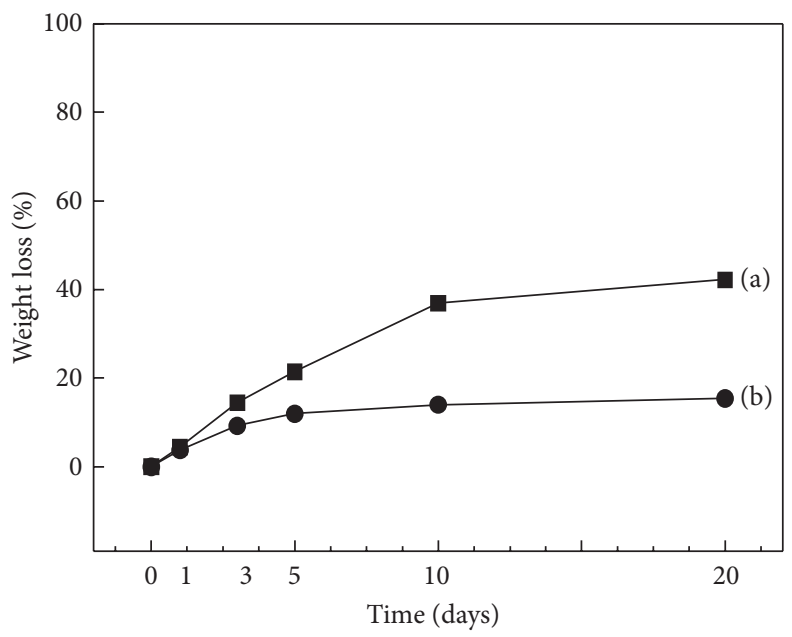

FIGURE 18: Weight loss (\%) of (a) kenaf/SPI-PVA composite without GA and (b) kenaf/SPI-PVA composite having 8 wt\% of GA with compost time.

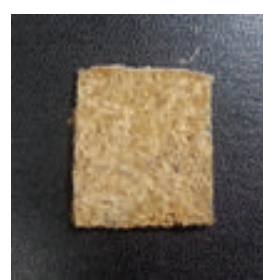

0 days

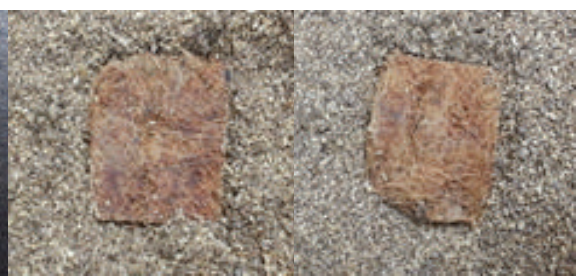

10 days
20 days

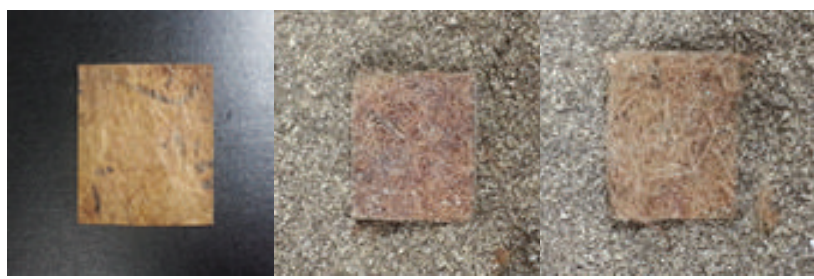

0 days
10 days

(b)

FIGURE 19: Photographs of the kenaf/SPI-PVA composite with compost time: (a) kenaf/SPI-PVA composites without GA, (b) kenaf/SPI-PVA composites with GA.

\section{Acknowledgments}

This research was financially supported by the Fundamental R\&D Program for Technology of the Graduate Student Education Program for Research of Hybrid and Super Fiber Materials through the Ministry of Trade, Industry \& Energy (MOTIE), and Korea Institute for Advancement of Technology (KIAT) (N0000993).

\section{References}

[1] J.-F. Su, X.-Y. Yuan, Z. Huang, and W.-L. Xia, "Properties stability and biodegradation behaviors of soy protein isolate/poly (vinyl alcohol) blend films," Polymer Degradation and Stability, vol. 95, no. 7, pp. 1226-1237, 2010.

[2] J.-F. Su, Z. Huang, K. Liu, L.-L. Fu, and H.-R. Liu, "Mechanical properties, biodegradation and water vapor permeability of blend films of soy protein isolate and poly (vinyl alcohol) compatibilized by glycerol," Polymer Bulletin, vol. 58, no. 5-6, pp. 913-921, 2007.

[3] R. M. D. Soares, F. F. Scremin, and V. Soldi, “Thermal stability of biodegradable films based on soy protein and corn starch," Macromolecular Symposia, vol. 229, pp. 258-265, 2005.
[4] N. Gontard, C. Duchez, J. L. Cuq, and S. Guilbert, "Edible composite films of wheat gluten and lipids: water vapour permeability and other physical properties," International Journal of Food Science \& Technology, vol. 29, no. 1, pp. 39-50, 1994.

[5] J. W. Rhim, J. H. Lee, and P. K. W. Ng, "Mechanical and barrier properties of biodegradable soy protein isolate-based films coated with polylactic acid," LWT-Food Science and Technology, vol. 40, no. 2, pp. 232-238, 2007.

[6] S. Chabba and A. N. Netravali, “Green' composites part 1: characterization of flax fabric and glutaraldehyde modified soy protein concentrate composites," Journal of Materials Science, vol. 40, no. 23, pp. 6263-6273, 2005.

[7] A. Biswas, R. L. Shogren, and J. L. Willett, "Solvent-free process to esterify polysaccharides," Biomacromolecules, vol. 6, no. 4, pp. 1843-1845, 2005.

[8] F. Gellerstedt and P. Gatenholm, "Surface properties of lignocellulosic fibers bearing carboxylic groups," Cellulose, vol. 6, no. 2, pp. 103-121, 1999.

[9] E. Zini, M. Scandola, and P. Getenholm, "Heterogeneous acylation of flax fibers. Reaction kinetics and surface properties," Biomacromolecules, vol. 4, no. 3, pp. 821-827, 2003.

[10] S. Chabba, G. F. Matthews, and A. N. Netravali, “'Green' composites using cross-linked soy flour and flax yarns," Green Chemistry, vol. 7, no. 8, pp. 576-581, 2005. 
[11] J. F. Su, Z. Huang, Y. H. Zhao, X. Y. Yuan, X. Y. Wang, and M. Li, "Moisture sorption and water vapor permeability of soy protein isolate/poly(vinyl alcohol)/glycerol blend films," Industrial Crops and Products, vol. 31, no. 2, pp. 266-276, 2010.

[12] J.-F. Su, X.-Y. Wang, Z. Huang et al., "Heat-sealing properties of soy protein isolate/poly(vinyl alcohol) blend films: effect of the heat-sealing temperature," Journal of Applied Polymer Science, vol. 115, no. 3, pp. 1901-1911, 2010.

[13] N. Limpan, T. Prodpran, S. Benjakul, and S. Prasarpran, "Influences of degree of hydrolysis and molecular weight of poly(vinyl alcohol) (PVA) on properties of fish myofibrillar protein/PVA blend films," Food Hydrocolloids, vol. 29, no. 1, pp. 226-233, 2012.

[14] V. Fiore, G. di Bella, and A. Valenza, "The effect of alkaline treatment on mechanical properties of kenaf fibers and their epoxy composites," Composites Part B: Engineering, vol. 68, pp. 14-21, 2015.

[15] H. M. Akil, M. F. Omar, A. A. M. Mazuki, S. Safiee, Z. A. M. Ishak, and A. Abu Bakar, "Kenaf fiber reinforced composites: a review," Materials \& Design, vol. 32, no. 8-9, pp. 4107-4121, 2011.

[16] B. Tajeddin, R. A. Rahman, L. C. Abdulah, N. A. Ibrahim, and Y. A. Yusof, "Thermal properties of low density polyethylenefilled kenaf cellulose composites," European Journal of Scientific Research, vol. 32, no. 2, pp. 223-230, 2009.

[17] M. Avella, G. Bogoeva-Gaceva, A. Bužarovska, M. E. Errico, G. Gentile, and A. Grozdanov, "Poly(lactic acid)-based biocomposites reinforced with kenaf fibers," Journal of Applied Polymer Science, vol. 108, no. 6, pp. 3542-3551, 2008.

[18] S. Rassmann, R. Paskaramoorthy, and R. G. Reid, "Effect of resin system on the mechanical properties and water absorption of kenaf fibre reinforced laminates," Materials \& Design, vol. 32, no. 3, pp. 1399-1406, 2011.

[19] A. Magurno, "Vegetable fibres in automotive interior components," Angewandte Makromolekulare Chemie, vol. 272, no. 1, pp. 99-107, 1999.

[20] M. M. Davoodi, S. M. Sapuan, D. Ahmad, A. Ali, A. Khalina, and M. Jonoobi, "Mechanical properties of hybrid kenaf/glass reinforced epoxy composite for passenger car bumper beam," Materials \& Design, vol. 31, no. 10, pp. 4927-4932, 2010.

[21] S. Serizawa, K. Inoue, and M. Iji, "Kenaf-fiber-reinforced poly(lactic acid) used for electronic products," Journal of Applied Polymer Science, vol. 100, no. 1, pp. 618-624, 2006.

[22] J. S. Won, T. S. Lee, H. S. Kim et al., "Preparation and characterization of Kenaf/Soy protein biocomposites," Journal of Biobased Materials and Bioenergy, vol. 8, no. 2, pp. 221-229, 2014.

[23] J.-F. Su, Z. Huang, C.-M. Yang, and X.-Y. Yuan, "Properties of soy protein isolate/poly(vinyl alcohol) blend 'green' films: compatibility, mechanical properties, and thermal stability," Journal of Applied Polymer Science, vol. 110, no. 6, pp. 3706-3716, 2008.

[24] P. Lodha and A. N. Netravali, "Thermal and mechanical properties of environment-friendly 'green' plastics from stearic acid modified-soy protein isolate," Industrial Crops and Products, vol. 21, no. 1, pp. 49-64, 2005.

[25] P. Lodha and A. N. Netravali, "Characterization of stearic acid modified soy protein isolate resin and ramie fiber reinforced 'green' composites,' Composites Science and Technology, vol. 65, no. 7-8, pp. 1211-1225, 2005.
[26] L. Rey, J. Duchet, J. Galy, H. Sautereau, D. Vouagner, and L. Carrion, "Structural heterogeneities and mechanical properties of vinyl/dimethacrylate networks synthesized by thermal free radical polymerisation," Polymer, vol. 43, no. 16, pp. 4375-4384, 2002.

[27] S. K. Park, D. H. Bae, and K. C. Rhee, "Soy protein biopolymers cross-linked with glutaraldehyde," Journal of the American Oil Chemists' Society, vol. 77, no. 8, pp. 879-883, 2000. 

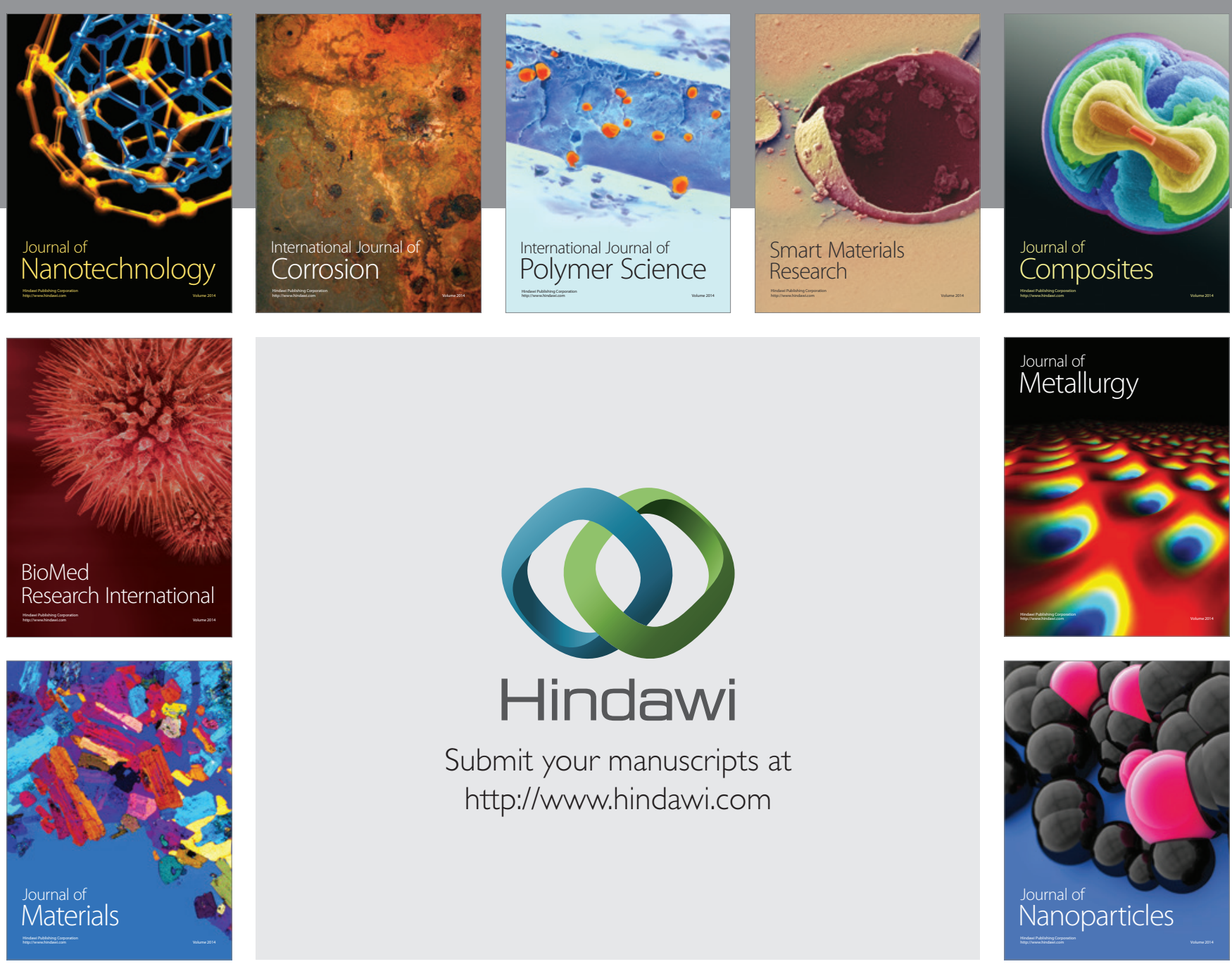

Submit your manuscripts at http://www.hindawi.com
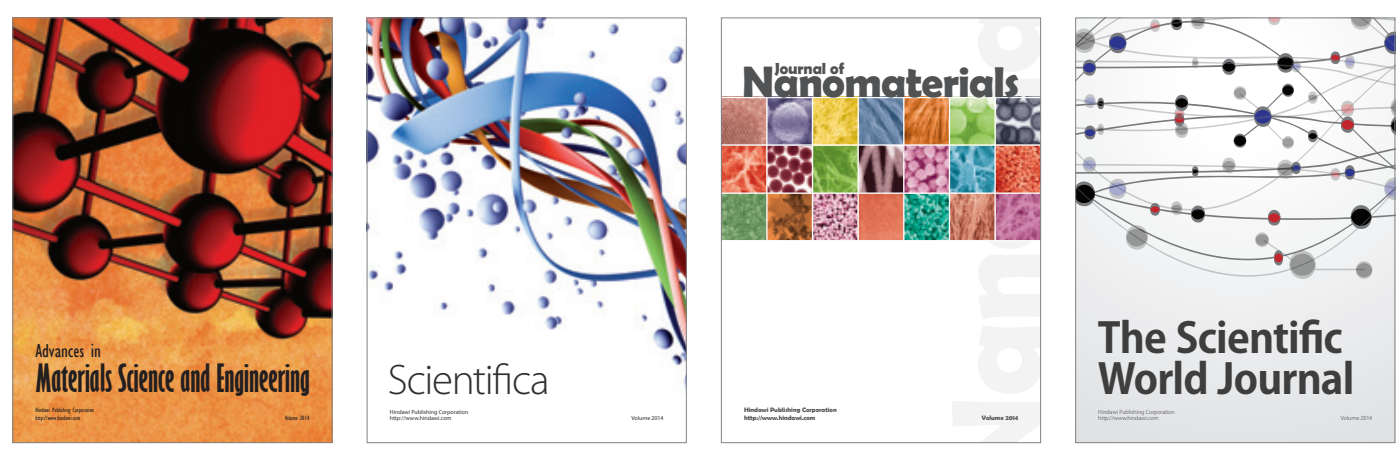

\section{The Scientific World Journal}
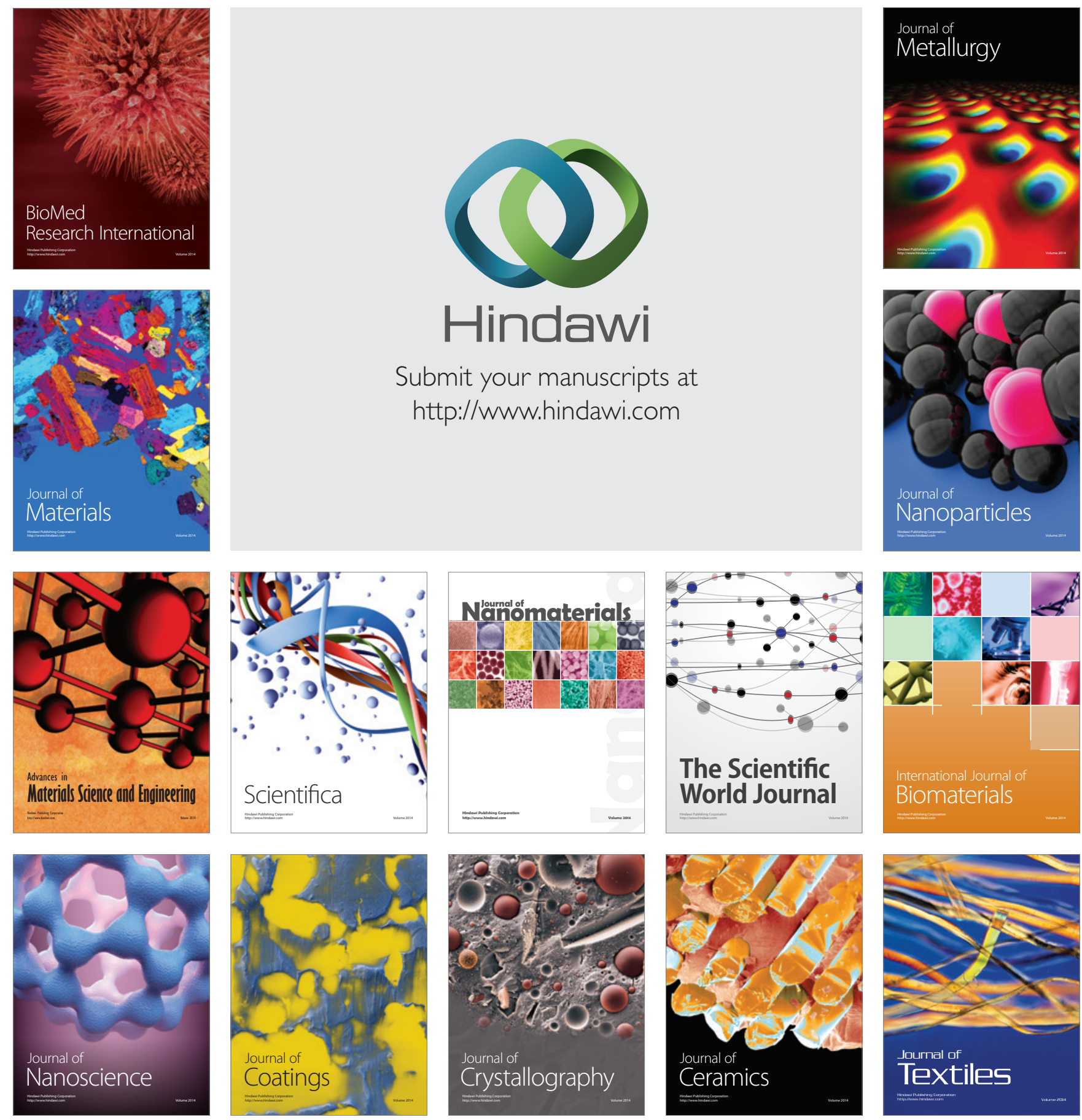